\title{
Correction to: Association between maternal polycystic ovary syndrome and early childhood growth: a continuous observation from 3 months to 6 years of age
}

\author{
Fangfang Zhang ${ }^{1} \cdot$ Liying Ying $^{1,2}$ - Qing Zhang ${ }^{1} \cdot$ Fangfang Wang $^{1} \cdot$ Fan $\mathrm{Qu}^{1}$ (1) \\ Published online: 31 January 2022 \\ (c) The Author(s), under exclusive licence to Springer Science+Business Media, LLC, part of Springer Nature 2022
}

\section{Correction to: Journal of Assisted Reproduction and Genetics} https://doi.org/10.1007/s10815-021-02378-9

The original article unfortunately was published with errors. The article note "Fangfang Zhang and Liying Ying contributed equally to the present study" was incorrectly placed in the Keyword section and Fan Qu should be the only corresponding author.

The original article has been corrected.

Publisher's note Springer Nature remains neutral with regard to jurisdictional claims in published maps and institutional affiliations.

The original article can be found online at https://doi.org/10.1007/ s10815-021-02378-9.

Fan $\mathrm{Qu}$

syqufan@zju.edu.cn

1 Women's Hospital, School of Medicine, Zhejiang University, 1 Xueshi Road, Hangzhou 310006, People's Republic of China

2 Ningbo Yinzhou No.2 Hospital, Ningbo, Zhejiang 315100, People's Republic of China 